\title{
Nature of Steel Effect on Intermetallic Compounds Obtained by Galvanization
}

\author{
Younes Benarioua ${ }^{a} *$ and Didier Chicot $^{b}$ \\ ${ }^{a}$ Département de Génie Mécanique, Faculté de Technologie, Université de M'sila BP 166 Ichbilia 28000 M'sila, Algérie \\ ${ }^{b}$ Université Lille Nord de France, Lille1, LML, UMR 8107, F-59650 Villeneuve d'Ascq, France
}

\begin{abstract}
Zinc and some of its alloys have a number of characteristics that make it well suited for use as a protective coating against the corrosion of steel substrates under severe atmospheric conditions. The metal of zinc, which represents the main galvanization element offer then a cathodic protection to the ferrous materials. Because of these excellent characteristics, galvanization coatings are expected to be used for different protective applications fields. The objective of this work is to study the influence of the nature of steel substrate on the microstructure and the hardness of the intermetallic compounds. The steels used as the substrate are employed in agriculture field as tubes and irrigation elements in pivot. After an optimal preparation of the surface of the substrate by an appropriate roughness process, the steels specimen were immersed in a molten zinc bath maintained at $450^{\circ} \mathrm{C}$. The chemical reactions which take place between the steel and the liquid zinc give rise to the formation of the $\delta$ and $\xi$ intermetallic compounds and the $\eta-\mathrm{Fe} / \mathrm{Zn}$ solid solution. The structure of coating was identified by $\mathrm{X}$ ray diffraction. The morphology and thickness of phases formed the coatings at different parameters took place with optical microscope. Finally the hardness of coatings was measured with a Vickers hardness tester.
\end{abstract}

Keywords: Steel, Zinc, Iron, Galvanization.

\section{Introduction}

The use of zinc galvanization coatings deposited onto steel is one of the most important commercial processing techniques employed to protect steel components exposed to severe corrosive environments. From a technological point of view, the principle of galvanizing has remained unchanged since such coatings are employed over 200 years ago [1-9]. The $\mathrm{Zn}$ protective coating structure consists of intermetallic $\mathrm{Fe}-\mathrm{Zn}$ compound layers, which have been identified as different phases coated by an outer layer rich in $\mathrm{Zn}$. The gamma phase which appears as a layer located close to the steel material, is only seen when the immersion time is relatively long. Delta and zeta phases are immediately seen and present an important thickness. The eta phase is the outermost phase found on these coatings, and it is basically made of pure zinc, and formed on the surface at the moment of the coating solidification.

${ }^{*}$ Corresponding author

E-mail: benariouayounes@yahoo.fr

(C) 2010 International Association for Sharing Knowledge and Sustainability.

DOI:10.5383/ijtee.11.01.007
However, these intermetallic layers which composed of $\Gamma, \delta$ and $\zeta$ phases are developed in accord with a Fe-Zn binary phase diagram [3-7]. The main objective of this work is to study the influence of the nature of steel on the structure, morphology, thickness and hardness of the different layers taking place into the hot-dip galvanizing coating. The hot-dip galvanizing coatings were obtained at the constant temperature of $450^{\circ} \mathrm{C}$ during immersion time of 30 minutes. The microstructure of the coating was analysed by X-Ray diffraction jointly to optical observations. The kinetic growth of the different layers is characterized by a power law connecting the layer thickness and the bath immersion time. The hardness of the coating is studied by classical Vickers microindentation.

\section{Iron-zinc phase formation}

When iron is immersed in molten zinc at the typical galvanizing temperatures and according to the Fe-Zn system, Horstmann 
[1,7] proposed that the following layers should form: zinc saturated $\alpha$-iron, $\Gamma$-phase layer, $\delta$-phase layer, $\xi$-phase layer and $\eta$-phase layer. Fe-Zn phase diagram which modified at several times, has been the subject of a number of research papers [1,2]. Zinc rich corner of this binary phase diagram is presented in Figure 1

According to the phase diagram part and at low temperature treatment, double layers of gamma $\left(\Gamma-\mathrm{Fe}_{5} \mathrm{Zn}_{21}\right.$ and $\left.\Gamma-\mathrm{Fe}_{3} \mathrm{Zn}_{10}\right)$ phases can form at the interface between the iron and the delta $\delta$-phase layer. Between 550 and $665 \mathrm{C}$, only the gamma $(\Gamma)$ phase layer is stable along with the constant thickness delta $(\delta$ $\mathrm{FeZn} 10)$ phase layer. Above $665 \mathrm{C}$, the delta $(\delta)$ phase layer is no longer stable and only a gamma $(\Gamma)$ phase layer forms. Since there is no evidence for flaking of the gamma $(\Gamma)$ phase layer, this layer probably grows in the linear region just as it grows in both the lower parabolic and upper parabolic regions [6].

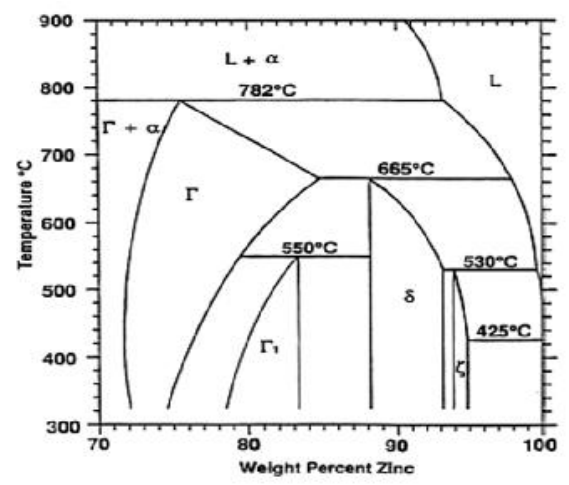

Fig.1. Zinc Rich Corner of the Fe-Zn Binary Phase Diagram [2]

The zeta phase $\left(\xi-\mathrm{FeZn}_{13}\right)$ has an iron content of approximately $5-6 \mathrm{wt} \%$ [2]. This phase is formed from the peritectic reaction between the delta $(\delta)$ phase and eta $(\eta)$ phase which present a liquid of zinc contained iron solute. $\eta-\mathrm{Zn}$ phase which present a solid solution at lower iron concentration is not represented in this system. The phases and characteristics of intermetallic compounds found in the diagram of Fe- $\mathrm{Zn}$ are outlined in tab. 1

Table 1. Fe-Zn Phase Characteristics

\begin{tabular}{|l|l|l|l|}
\hline Phase & Formula & structure & HVN \\
\hline$\alpha-\mathbf{F e}$ & Fe(Zn) & BCC & 104 \\
\hline$\Gamma$ & Fe3Zn10 & BCC & $336[2]$ \\
\hline$\Gamma \mathbf{1}$ & Fe5Zn21 & FCC & $505[2]$ \\
\hline$\delta \mathbf{k}$ & FeZn7 & Hexagonal & $280-258[10]$ \\
\hline$\delta \mathbf{p}$ & FeZn10 & & $200[10]$ \\
\hline$\xi$ & FeZn13 & Monoclinic & $140[2]$, \\
\hline$\eta-Z n$ & Fe)Zn & HCP & $52[2]$, \\
\hline
\end{tabular}

The primary phases formed during time immersion galvanizing are gamma $(\Gamma)$, delta $(\delta)$, zeta $(\xi)$ and eta $(\eta)$. The $\Gamma$ phase appears as a layer located close to the base material, and it is only seen when the immersion time is relatively long. On the other hand, $\delta$ and $\xi$ phases are immediately seen between the inner and outer layer. The phase of $\delta$ present two superposed layers $\left(\delta_{\mathrm{k}}\right.$ and $\left.\delta_{\mathrm{p}}\right)$ witch present a same physical characteristics but different at point of view metallographic structure.

The phase of $\delta_{\mathrm{k}}$ compact and palisade $\delta_{\mathrm{p}}$ present respectively a thin continuous strip film side $\Gamma$ and a thicker strip microcrack side $\zeta$. Adjacent to the delta $(\delta)$ phase layer, the zeta $(\xi)$ phase grows in a columnar morphology that is super-saturated in Fe. The zeta ( $\xi$ ) phase has two layers depending upon the supersaturation of $\mathrm{Fe}$ in the melt. The $\eta$ phase is the outer most phases found on these coatings, and it is basically made of pure zinc, and formed on the surface at the moment of the coating solidification.

\section{Materials experimental results}

The materials constituting the substrates are a low-carbon steels with the chemical composition containing were indicated in table 1 . This various steel submitted to galvanizing were used in agriculture as tube and a watering pivot. Prior to the galvanization, the steel samples were initially prepared by following three distinct steeps. These specimens of three steel have identical surface and three thickness of 5, 10 and $20 \mathrm{~mm}$ were initially degreased, picked in an aqueous solution containing $16 \%$ of $\mathrm{H}_{2} \mathrm{SO}_{4}$ and fluxed in an aqueous solution containing $\mathrm{ZnCl}_{2}$ and $2 \mathrm{NH}_{4} \mathrm{Cl}$. Finally, the samples were dipped into the galvanizing bath containing the chemical composition of $0.40 \% \mathrm{Cd}, 1.4 \% \mathrm{~Pb}, 0.05 \% \mathrm{Fe}, 0.08 \% \mathrm{Cu}, 4.5 \% \mathrm{Al}$ and $\mathrm{Zn}$ in balance. The molten zinc was heated in furnace by using an electric resistance. During the immersion time of $30 \mathrm{~min}$, the coating was carried out in the galvanizing bath at the temperature of about $450{ }^{\circ} \mathrm{C}$. The control of bath temperature was ensured by a thermocouple. The samples were then quenched immediately in water upon removal from the bath in order to preserve the structure existing at the end of the galvanizing reaction.

Table 2. Chemical Composition of Steels Substrates

\begin{tabular}{|l|l|l|l|l|l|l|}
\hline Element & $\mathrm{C}$ & $\mathrm{Si}$ & $\mathrm{Mn}$ & $\mathrm{Mo}$ & $\mathrm{Ni}$ & $\mathrm{Al}$ \\
\hline $\mathrm{S} 1$ & 0.20 & 0.05 & 0.03 & 0.01 & 0.03 & 0.07 \\
\hline S2 & 0.17 & 0.02 & 0.05 & 0.07 & 0.01 & 0.01 \\
\hline S3 & 0.10 & 0.02 & 0.70 & 0.13 & 0.01 & 0.06 \\
\hline
\end{tabular}

The structure of the coatings is analyzed by Y-Ray diffraction using a Inel diffractometer with a monochromatic $\operatorname{Co}(K \alpha)$ radiation. The observation of the microstructure is performed on a cross-section of the galvanized samples which have been previously cut and mounted in Bakelite resin. Afterwards, the samples are polished up to $0.2 \mu \mathrm{m}$ alumina emulsion. The specimens were then etched in the Nital solution saturated with $2 \%$ of nitric acid. The observations were made by means of a Nikon optical microscopy. The thickness of the different galvanization layers formed on the steel substrate was measured by optical microscopy. Hardness was determined using a Leco microhardness tester with a Vickers indenter. At least three indentation experiments were performed at each indentation load in order to obtain a representative hardness value. The hardness-depth profile along a cross section was obtained by applying the indentation load of $25 \mathrm{~g}$. 


\section{Results and Discussion}

\subsection{Morphology and microstructure.}

X-Ray Diffraction spectra of the galvanized coatings obtained on three steels of substrates after bath immersion time of $30 \mathrm{~min}$ were shown in Figure 2.

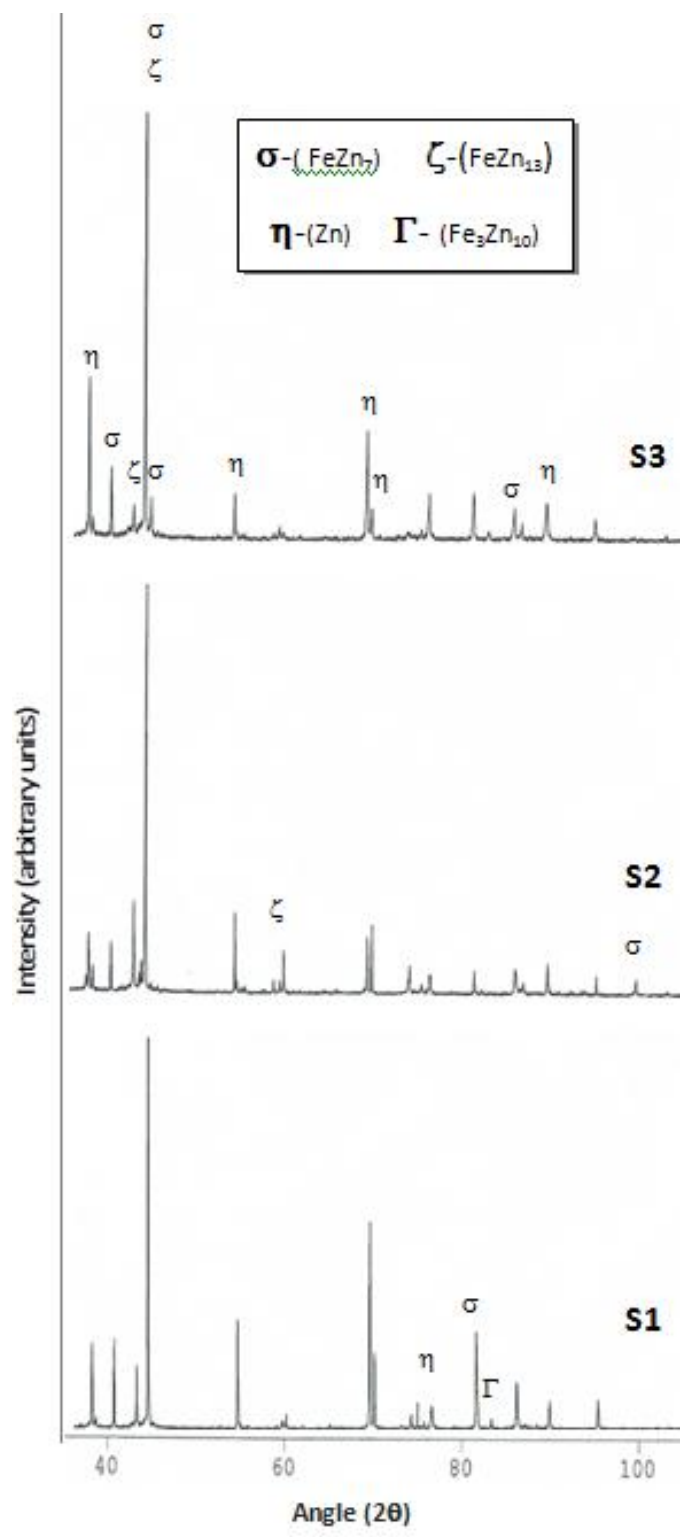

Figure 2. X-ray Diffraction Spectra of Galvanization Coating Obtained on three steels S1, S2 and S3

In this figure, the XRD measurements reveal the presence of $\eta$ $\mathrm{Zn}, \quad \xi-\mathrm{FeZn}_{13}$ and $\sigma-\mathrm{FeZn}_{7}$ phases. According to the galvanization conditions employed in this work, the phases of $\eta$, $\xi$, and $\sigma$ were presented in high proportion as revealed by their picks witch have a considerable intensity of diffraction. The inner phase of $\Gamma$ is detectible by XRD in three samples as a negligible pick of diffraction.
Figure 3 shows the typical microstructures of the coating obtained on three different steel after immersion time of $30 \mathrm{~min}$. The phase of $\Gamma-\mathrm{Fe}_{3} \mathrm{Zn}_{10}$ appears as a black line in a very thin layer with a planar interface between the steel substrate and the delta-phase.
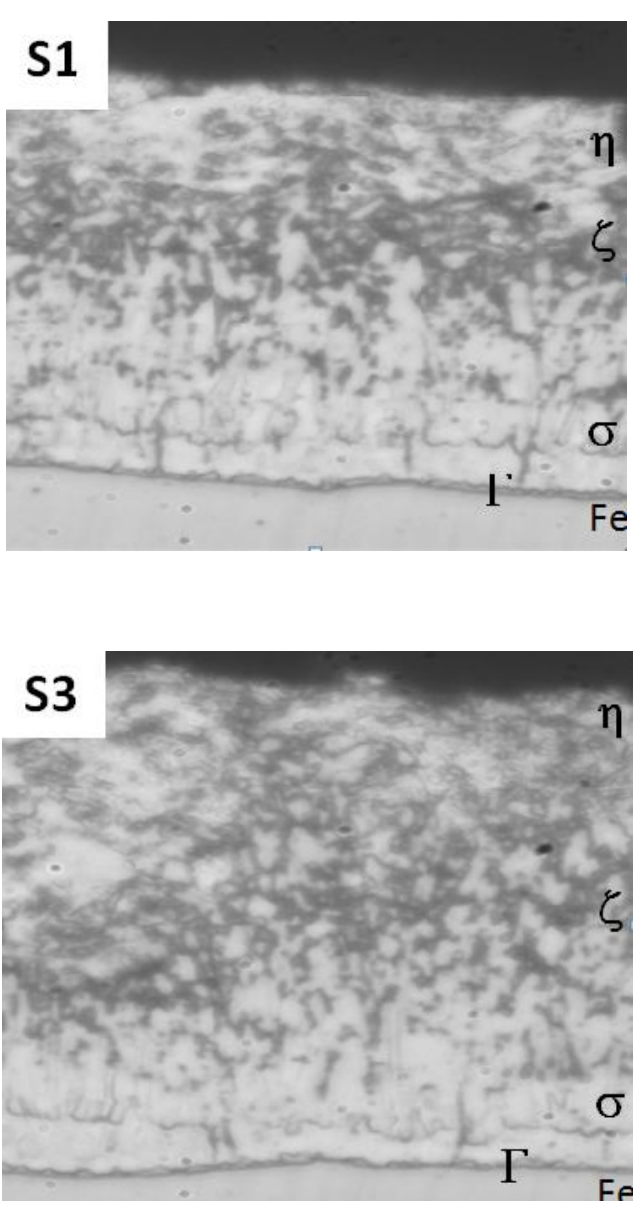

Figure 3. Optical micrographs of the Coatings Obtained on Two Steels S1 and S3

The $\sigma$-phase presents a columnar morphology as a result of a preferred growth perpendicular to the interface in a direction along the basal plan of the coating structure. The phase of $\sigma$ witch has two distinct zones $\sigma_{\mathrm{k}}$ and $\sigma_{\mathrm{p}}$ placed between the phases of $\Gamma$ and $\zeta$. Adjacent to the delta $\left(\sigma_{\mathrm{k}}\right)$ phase layer, $\zeta-\mathrm{FeZn} 13$ phase appears and grows in a columnar morphology. Continued growth of these inter layers occurs rather than the formation of new outer layer of $\eta-\mathrm{Zn}$ phase is formed. According to the nature of phases, the coating thickness of each layer obtained on three different steels substrate, as well as the whole coating thickness, are collected in Table 2 .

Table 2. Thickness of the Different Phases of Coating

\begin{tabular}{|c|c|c|c|}
\hline Phase $(\boldsymbol{\mu m})$ & S1 & S2 & S3 \\
\hline$\delta$ & 15 & 15 & 15 \\
\hline$\xi$ & 20 & 20 & 30 \\
\hline$\eta$ & 20 & 25 & 30 \\
\hline Coating & 55 & 60 & 75 \\
\hline
\end{tabular}


As shown in Figure 4, the galvanization coating obtained on the steel type of S1, S2 and S3 is varied. This variation of thickness can be explained by the chemical composition of steels. We notice that the manganese element play an important role in the increase of the coating galvanization.

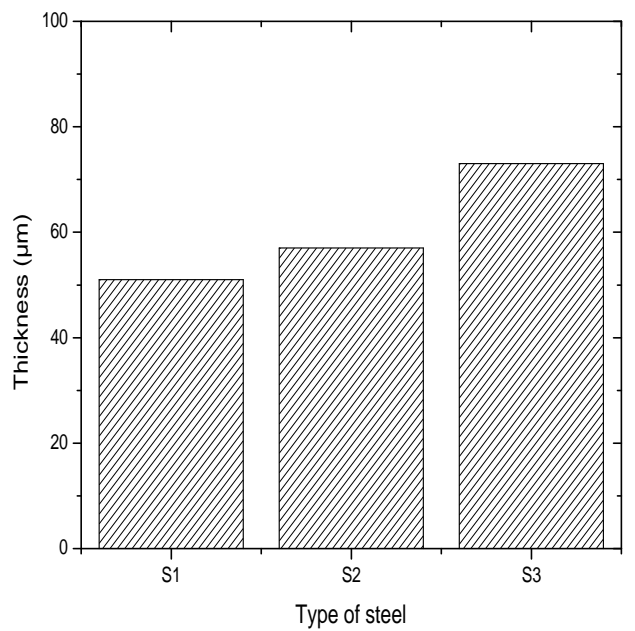

Fig.4. Variation of Thickness of Coating Galvanized Obtained on Three Steels S1, S2 and S3

\subsection{Hardness}

In order to study the hardness of galvanization coatings, we perform first Vickers indentation for a load of $0.25 \mathrm{~N}$ and at least three indentations using a LECO microhardness tester. To determine the evolution of intrinsic hardness from coating and substrate, a hardness profile has been applied. A series of microhardness indentations at load of $0.25 \mathrm{~N}$ was performed on polished sections of three specimen galvanized.

Hardness profiles obtained for the galvanized samples are shown in Figure 5. For three chosen type of steel substrate, it is shown that the profile hardness present different zones. For the first zone corresponding to the steel substrate, no hardness variation was found after different treatment time. The hardness reaches maximum values corresponding to delta phase. This properties was successively decreased and take respectively the values corresponding to zeta and eta phases.

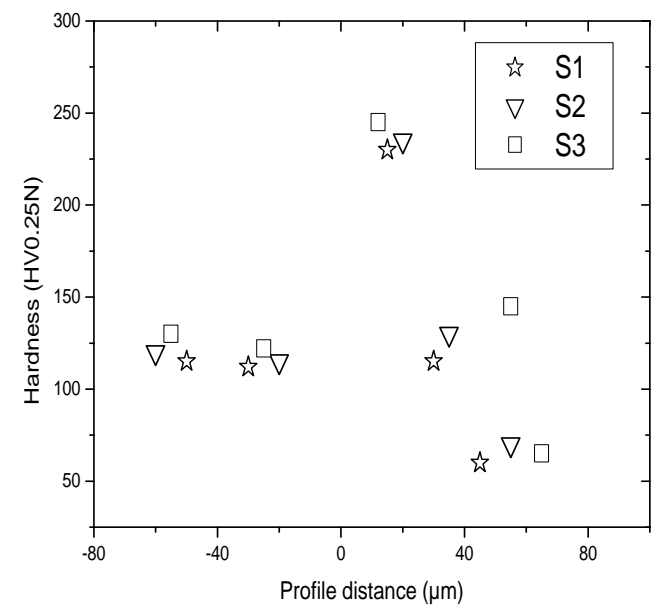

Figure 5. Hardness Depth-Profile Obtained on the Cross-Sections of the Coatings Obtained on Three Steels S1, S2 and S3

\section{Conclusion}

The coatings of galvanization were used as treatment to improve chemical and mechanical properties of steels. The coating obtained on different type steels present heterogeneous layer of $\sigma, \xi$ and $\eta$-phase. It was found, that the formation of $\Gamma$-phase was detected by XRD for tree samples as low pick of diffraction. Relative to this last phase, the other phases of $\sigma, \xi$ and $\eta$ present an important thickness.

\section{References}

[1] D. Horstmann, Reaction between iron and zinc, Zinc Development Association, London 1978

[2] A.R. Marder, The metallurgy of zinc-coated steel, Mater. Sci. 45 (2000) 191.

[3] P.Bicao, W. Jianhua, S. Xuping , L. Zhi, Y. Fucheng, Effects of Zinc bath temperature on the coatings of hotdip galvanizing, Surface \& Coatings Technology 202 (2008) 1785-1788

[4] D. Horstmann, F K Peters. The reaction between iron and zinc. Proceeding of $9^{\text {th }}$ International Hot Dip Galvanization Conference. London: Zinc Development Association, 1971

[5] C.E. Jordan, A.R. Marder. Fe-Zn phase formation in interstitial free steels hot-dip galvanized at $450^{\circ} \mathrm{C}$, Part I. J Mater Sci 1997;32: 55- 93.

[6] D. Horstmann; Formation and growth of iron - zinc alloy layers. Proceeding of $14^{\text {th }}$ International Hot Dip Galvanization Conference. London; 1986. p. 6-1.

[7] M. Onishi, Y. Wakamatsu, H. Miura, Formation and growth kinetics of intermediate phases in $\mathrm{Fe}-\mathrm{Zn}$ diffusion couples. Trans JIM 1974

[8] G.F. Bastin, F.J.J. van Loo, G.D. Rieck, A New Compound in the Iron Zinc System. Z Metallkde 1977.

[9] C.E. Jordon, A.R. Marder, J. Mater. Sci. 32 (1997); 5593.

[10] G. Vourlias, N. Pistofidis, G. Stergioudis, D. Tsipas ; The effect of alloying elements on the Crystallization behaviour and on the properties of galvanized coatings; Cryst. Res. No. 1, 23 -29 (2004)

[11] A.R.B. Verma, W.J. van Ooij, Surf. Coat. Technol. 89 (1997) 143

[12] J.H. Hong , S.J. Oh S. J. Kwon, Intermetallics 11 (2003) 207. 